\title{
Erratum
}

\section{Erratum to: Variation of cassiicolin genes among Chinese isolates of Corynespora cassiicola}

\author{
Jun $\mathrm{Wu}^{1,2}$, Xuewen Xie ${ }^{1}$, Yanxia Shi ${ }^{1}$, Ali Chai ${ }^{1}$, Qi Wang ${ }^{2}$, and Baoju $\mathrm{Li}^{1 *}$ \\ ${ }^{1}$ Institute of Vegetables and Flowers, Chinese Academy of Agricultural Sciences, Beijing 10081, P. R. China \\ ${ }^{2}$ Department of Plant Pathology, China Agricultural University, Beijing 100094, P. R. China
}

In the online published article by Wu et al. since 30 July 2018, the figure 4 is unfortunately incorrect. The figure 4 should be corrected as below.

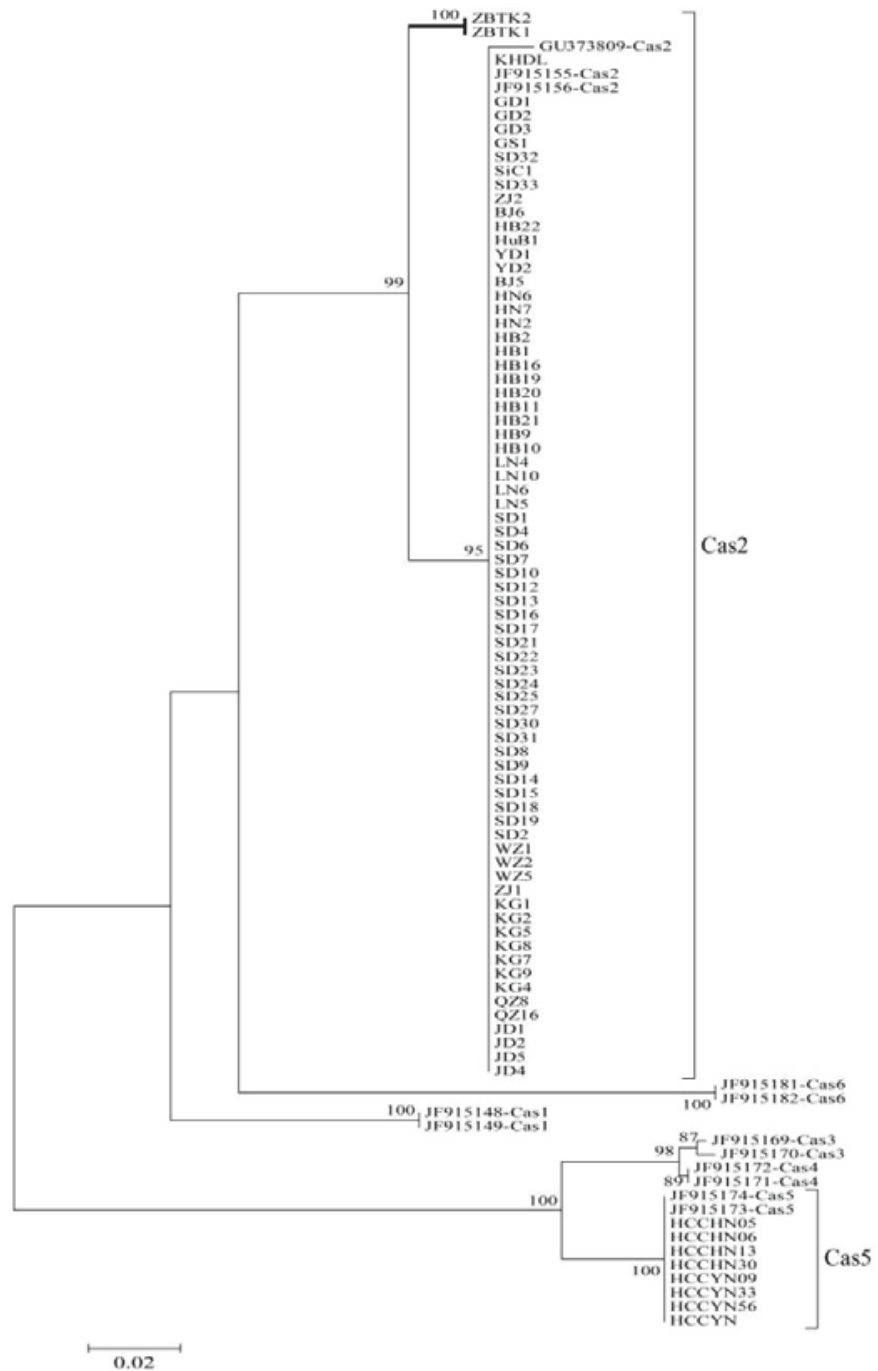

The online version of the original article can be found at https://doi.org/10.1007/s12275-018-7497-5. 